\title{
Structure of readiness of pedagogical university students for prevention of addictive behavior
}

\author{
E.G. Shubnikova ${ }^{1 *}$ \\ ${ }^{1}$ I. Yakovlev Chuvash State Pedagogical University, Cheboksary, Russia
}

\begin{abstract}
The spread of addictive behavior among minors continues to be a dangerous trend about children and young people. Therefore, one of the most important areas of pedagogical activity is the prevention of addictions in educational organizations, as well as the training of pedagogical university students for being able to prevent addictions in children and adolescents. The study considers the structure of pedagogical university students' readiness for the prevention of addictions in the educational environment, relying on a competence-based approach. We have proposed a characteristic of the model for assessing the competence of future teachers in the prevention of addictive behavior in children and young people. We considered the content of the training of future teachers for the prevention of addictive behavior based on the study of preventive pedagogy, and analyzed the main approaches to the prevention of addictive behavior in the educational environment. We presented the results of an experimental study and revealed the effectiveness of the training of pedagogical university students for preventive activities with adolescents.
\end{abstract}

\section{A problem statement}

Despite the adoption of the "Strategy of the Russian Federation National Anti-Drug Policy until 2020" (2010), the "Concept for the Prevention of Psychoactive Substance Use in Educational Environment" (2011) and many other legislative documents, the effectiveness of preventive pedagogical activity remains low. These normative documents again and again raise the issue of the need for the training of teaching staff for preventive work among children and young people. The "Concept for the Prevention of Psychoactive Substance Use in Educational Environment" (2011) indicates that primary pedagogical prevention plays a leading role in the prevention of substance use in the educational environment. However, the situation remains as it is. In our opinion, the reason for this is the lack of clear requirements for the teacher's competences in the field of preventive activities $[1,2,3]$.

However, our survey of 100 teachers, psychologists and social teachers of educational organizations of the Chuvash Republic showed that one of the main forms of prevention of addictive behavior in children and adolescents is still a preventive conversation, an anti-

\footnotetext{
* Corresponding author: prof-ped.gpa@mail.ru
} 
drug lecture, and anti-drug measures taken within the months of struggle against drug addiction. We have revealed the fact that school teachers, psychologists and social teachers do not know modern social, psychological and pedagogical technologies for the prevention of the use of psychoactive substances among children and adolescents.

Most of the interviewed teachers are not familiar with the preventive programs approved by the Ministry of Education and Science of the Russian Federation. They have no experience in preventive activities. The measures taken by them are of chaotic and scattered character. Sometimes, such measures are rather advertising than preventive, arousing some prurient curiosity in children and adolescents on the use of psychoactive substances.

Despite the fact that nearly all the normative documents claim the need of the training of teaching staff for preventive work in the educational environment, the situation has not changed yet. As a rule, pedagogical university students are not familiar with the prevention programs. They do not know any modern technologies for the prevention of addictions in the educational environment $[4,5,6,7,8]$.

\subsection{The objective of the work}

Today, higher educational institutions train their students on the basis of the Federal State Educational Standard of Higher education of the 3rd Generation, which provides universities with the opportunity to independently develop the variable part of the training program. To increase the effectiveness of students' training for preventive activities in the educational environment, it is necessary to determine its content on the basis of teachers' professional standards, and to reveal the indicators of assessment and levels of readiness for preventive activities among children and adolescents.

In the Federal State Educational Institution of Higher Education in "Psychological and Pedagogical Education" training program, we would single out only "the ability to use health-saving technologies in professional activities, to take into account the risks and dangers of social and educational environment" in the group of professional competences in the field of pedagogical activity. The group of professional competences reflects the readiness of future teachers for specific professional activities and does not contain any competence in the prevention of addictive behavior in children and adolescents.

V.D. Shadrikov employed the structure and content of the psychological system of activity as an objective criterion for theoretically substantiated identification of the composition of the basic competences in any professional activity, including pedagogical activity. The activity competences identified by V.D. Shadrikov formed the basis for determining the corresponding competences that teachers should possess. We believe that there is an urgent need to develop the basic competences for the teacher's preventive activities [2, 3].

The concept of the system genesis developed by V.D. Shadrikov makes it possible to analyze various types of subject-to-subject activity including preventive activity on the basis of its key concept of the psychological system of activity. According to A.V. Karpov, the prospects for the development of the application-oriented aspect of the concept of the system genesis for managerial, organizational, informational types of professional activities become obvious [9].

\section{Results of the research}

Due to the recognition of the importance of the preventive activities of educational psychologists and social teachers, there have been included the following disciplines to 
form the competence in the field of prevention of addictive behavior in children and adolescents in the curriculum for the training of bachelors majoring in "Psychological and Pedagogical Education" on the educational program specialization "Psychology and Social Pedagogy" at FSBEI HE "I. Yakovlev Chuvash State Pedagogical University": "Professional Activity of a Social Teacher in Education", "Prevention of Addictive Behavior in Children", "Methods and Techniques of the Social Teacher's Activity", "Social and Psychological Training", "Methods of Active Social and Psychological Training", "Psychological and Pedagogical Correction", "Social and Pedagogical Projecting", "Health-saving Technologies in Education", "Social Protection of Childhood", "Psychology of Stress", etc. For all the courses there have been prepared academic course working programs and funds of assessment tools [3].

We have developed a model of basic competences for the teacher's preventive activities and the detailed characteristics of these competences. The development of the competences allowed us to analyze the effectiveness of the training of pedagogical university students of "Psychology and Social Pedagogy" and to analyze the progress in their implementing preventive activities in the educational environment during teaching practicum. We suggest considering these competences in detail.

1. Competence in the field of personal qualities;

2. Competence in setting goals and objectives for preventive activities;

3. Competence in motivating pupils to participate in preventive activity reflects the quality of the teacher's being able to motivate pupils' participation in preventive activities and motivate them to keep to a healthy behavior without the use of psychoactive substances;

4. Competence in providing informational basis for preventive activities;

5. Competence in developing new prevention programs;

6. Competence in organizing preventive activities $[10,11]$.

Thus, the components of the psychological structure of activity developed by V.D. Shadrikov in his theory of system genesis can serve the basis for the analysis of the teacher's preventive activities. The theoretical model of 6 units of competences for assessing students' readiness for preventive activities allows us to assess the level of pedagogical university students' readiness to prevent addictions in children and adolescents [1].

We have taught the students some theoretical basis for pedagogical prevention of addictive behavior in children and adolescents, as well as the methods of psychological diagnostics of children's coping behavior strategies and the level of development of their personal resources. As part of the course "Prevention of Addictive Behavior in Children" we have developed and conducted the classes on the following topics:

1) the essence and characteristics of the concept of addictive behavior, its types and reasons for it;

2) the risk factors and factors of protection against the use of psychoactive substances;

3 ) the legal framework for pedagogical prevention of addictive behavior in children and adolescents;

4) the "Concept for the Prevention of Psychoactive Substance Use in Educational Environment" (2011): structure and analysis;

5) the essence and characteristics of pedagogical prevention of addictive behavior in children and adolescents;

6) the main approaches and conceptual models for the prevention of addictive behavior in the educational environment; and some others [12, 4, 13, 14, 15, 16, 17].

All the students who took part in the experiment have successfully passed the course testing. 17 students (68\% of the participants) demonstrated an average course knowledge 
level, and 8 people (32\% of the respondents) showed a high course knowledge level in "Prevention of Addictive Behavior in Children".

For four months, 25 fourth-year students of "Psychology and Social Pedagogy" training program had been doing practice teaching. During this practice teaching, the students were assigned to the classes in which they taught the pupils coping behavior strategies and explained what personal resources are. The students also held classes on pedagogical prevention of addictive behavior in schoolchildren. The research results were reflected in the students' course papers.

1. After the analysis the students' practice teaching, the following results were obtained: the work on the formation of the $1^{\text {st }}$ Unit of assessment of students' competence in preventive activities "Unit of Personal Qualities" in terms of "Personal Readiness for Preventive Activites" gave positive results.

To diagnose coping behavior of students, we employed the "Coping Inventory for Stressful Situations (CISS)" technique by N. Endler and D. Parker (adapted by T.L. Kryukova) $[18,19]$. The risk factors and indicators of a low level of personal readiness formation are a low level of problem-oriented coping behavior and a high level of avoidance-oriented coping behavior. Basing on the analysis of these two factors, we concluded on the key model of coping behavior: an adaptive model (there are no risk factors), a pseudo-adaptive model (one of the risk factors was identified), a dezadaptive model (both risk factors were found).

In the first year in 16 students (64\% of the respondents) proved to have a low level of problem-oriented coping behavior, and in 11 students (44\% of the respondents) appeared to have a high level of avoidance-oriented coping behavior.

The results showed that $20 \%$ of the students use an adaptive coping behavior model, $52 \%$ of the respondents use a pseudo-adaptive coping behavior model, and $28 \%$ of the students proved to have the signs of dezadaptation. The analysis of the characteristics of the key coping behavior strategies demonstrates that there prevails an avoidance-oriented coping behavior model in this group (64\% of the respondents).

The analysis of the results of psychological diagnostics of the fourth-year students who had done the practice teaching showed that a low level of problem-oriented coping behavior was found in 3 students ( $12 \%$ of the respondents), and a high level of avoidance-oriented coping behavior was found in 4 students ( $16 \%$ of the respondents).

The results showed that 18 students use an adaptive model of coping behavior $(72 \%$ of the respondents), 7 students ( $28 \%$ of the students) use a pseudo-adaptive model of coping behavior, there were found no signs of maladjustment. The analysis of the characteristics of the main coping behavior strategies revealed that the problem-oriented coping behavior strategy dominates in this group ( $88 \%$ of the respondents) (Table 1).

Table 1. Results of diagnostic models coping behavior of students before and after forming experiment, (\%).

\begin{tabular}{|l|c|c|}
\hline \multicolumn{1}{|c|}{ Models coping behavior } & $\begin{array}{c}\text { Before the } \\
\text { experiment }\end{array}$ & After the experiment \\
\hline Adaptive & 20.0 & 72.0 \\
\hline Pseudoadaptive & 52.0 & 28.0 \\
\hline Dezadaptive & 28.0 & 0.0 \\
\hline
\end{tabular}

Thus, we found that, in general, by the end of the $4^{\text {th }}$ year of study, the pedagogical university students use both productive and unproductive coping behavior strategies, which contributes to their being more flexible and mobile when solving life problems.

The next 5 units of students' competences in preventive activity were assessed by practice teaching experts and by us (Figure 1). 


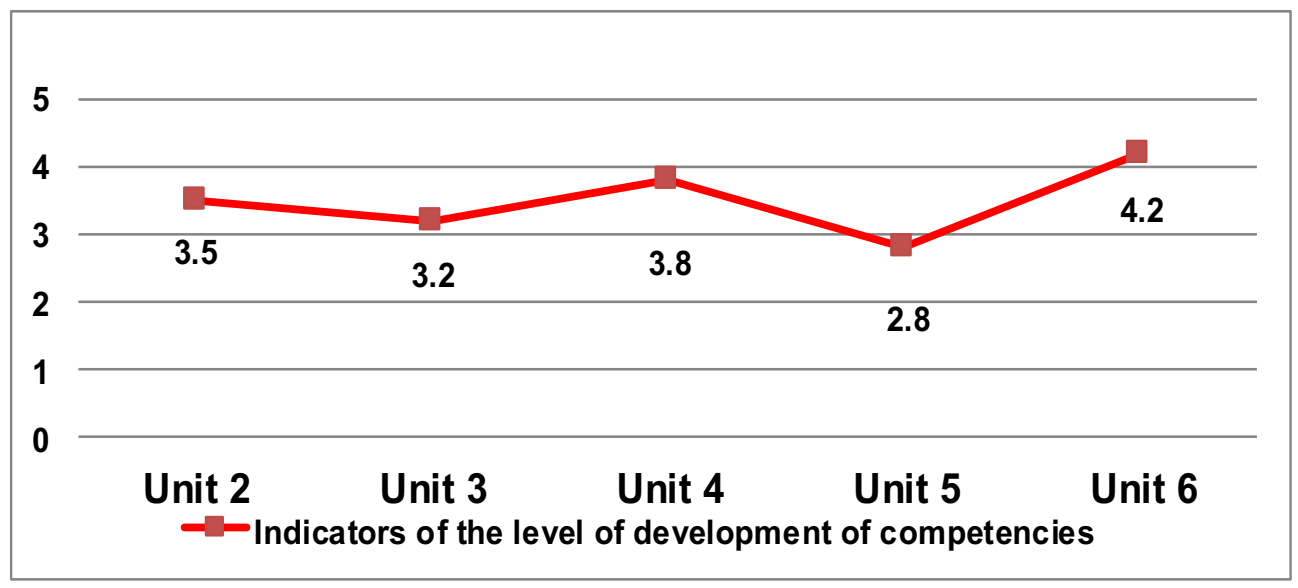

Fig. 1. Indicators of the formation of students' competencies in preventive activities based on the assessment of experts.

2. As a result of our study, it was revealed that the formation of Unit 2 "Competence in Setting Goals and Objectives for Preventive Activities" was assessed averagely at 3.5 points. The following remarks were made: the pedagogical university students do not have sufficient knowledge of the age and individual characteristics of pupils; they do not employ the analysis of risk factors and factors of protection against addictive behavior in their preventive work.

3. The formation of competences in Unit 3 "Competence in Motivating Pupils to Participate in Preventive Activities" was also assessed averagely at 3.2 points. The experts remarked that future educational psychologists are fluent in the use of interactive forms of conducting classes on the prevention of addictive behavior; however, due to the fact that they work with children for a short time, they find it difficult to motivate pupils to participate in preventive activities.

4. The formation of competences in Unit 4 "Competence in Providing Informational Basis for Preventive Activities" was assessed rather highly at 3.8 points, which corresponds to the average level of competence formation in preventive activities. The teaching methodology experts noted that the students know various approaches to prevention in the educational environment, have theoretical knowledge on coping prevention of addictions in adolescents, employ various techniques and methods of work in practice, but while copying the patterns of behavior and conducting classes, they have difficulties in developing and implementing of preventive activity classes independently.

5. The level of competence formation in Unit 5 "Competence in Developing New Prevention Programs" was assessed at 2.8 points as the lowest, which is a low level of formation. It should be noted that the students know the regulatory documents on the requirements for preventive activities; they independently conduct research on the effectiveness of preventive activities, but are not yet ready to independently develop new programs of preventive activities.

6. The formation of competences in Unit 6 "Competence in Organizing Preventive Activities" was assessed 4.2 points as the highest. It was remarked that the students of the experimental group are able to communicate with children, quickly find a common language with them, give schoolchildren the opportunity to express their point of view, and are skilled enough to conduct training sessions. However, sometimes they get lost in difficult pedagogical situations that arise in preventive activity and require a quick response to ongoing events. 


\section{Conclusions}

Thus, we can state that the conducted work provided an increase in the indicators of the formation of competences in preventive activities among pedagogical university students. However, it should be noted that, by and large, the training in a higher educational institution is not characterized by a clear target orientation towards the formation of students' readiness for preventive activities. Therefore, further implementation of the presented work experience in the educational process seems to be rather necessary. To increase the effectiveness of pedagogical prevention of addictive behavior in children and adolescents, it is necessary to teach pedagogical university lecturers, teachers and students modern pedagogical and psychological technologies based on the formation of professional competences in preventive pedagogical activity. We put these competences as the basis for developing the structure of the content and assessment of the effectiveness of training future teachers for the prevention of adolescents' addictions in the educational environment.

\section{References}

1. The concept of prevention of substance abuse in the educational environment, 13 (Moscow, 2011)

2. V.D. Shadrikov, Formation of Basic Competences by Activity-based Approach (as exemplified in Pedagogical Activity), World of Psychology, 3, 105-119 (2014)

3. E.G. Shubnikova, Pedagogical prevention technology of addictive behavior of children and youth, 154 (Moscow: Modern Education, 2015)

4. European drug prevention quality standards. A manual for prevention professionals, 292 (Luxembourg: Publications Office of the European Union, European Monitoring Centre for Drugs and Drug Addiction (EMCDDA), 2011)

5. G.A. Korchagina, E.V. Fadeeva, The Need for Introduction of Standards for the Primary Prevention of Psychoactive Substance Use in the Russian Federation, Narcology Problems, 6, 220-231 (2013)

6. E.B. Robertson, S.L. David, S.A. Rao, Preventing Drug Use among Children and Adolescents: A Research-Based Guide for Parents, Educators, and Community Leaders, 49 (Bethesda: NIDA, 2003)

7. E.G. Shubnikova, Methodological analysis of the approaches and models of addictive behavior prevention in the educational environment, Social pedagogy in Russia, 4, 2229 (2014)

8. E.G. Shubnikova, Pedagogical prevention of addictive behavior of children in the educational environment: the use of personal resources, Social pedagogics in Russia, 6, 25-30 (2015)

9. A.V. Karpov, From Psychology of Activity to Psychology of the Doer (review of "Psychology of Human Activity" by V.D. Shadrikov), World of Psychology, 3, 119133 (2014)

10. E.G. Shubnikova, Analysis of strategies of coping behavior of future pedagogues as markers of personal readiness for professional activity, Proceedings of the II International Scientific-Practical Conference «Psychology of Extreme Professions» (ISPCPEP 2019)

11. E.G. Shubnikova, A.N. Khuziakhmetov, D.P. Khanolainen, Internet-addiction of adolescents: diagnostic problems and pedagogical prevention in the educational 
environment, Eurasia Journal of Mathematics, Science and Technology Education, 13(8), 5261-5271 (2017)

12. J.D. Coie, N.F. Watt, G.W. Stephen, D. Hawakins, J.R. Asarnow, H.J. Markman, S.L. Ramey, M.B. Shure and B. Long, The Science of Prevention: Conceptual Framework and Some Directions for a National Research Program, American Psychologist, 48, 1013-1022 (1993)

13. S. Sagy, Preventing Drug Abuse among Children and Adolescents: Where Does the Salutogenic Approach Direct Us?, Health, 6, 541-548 (2014)

14. N.A. Sirota, V.M. Yaltonsky, N.S. Viderman, Prevention of addiction in adolescents: from theory to practice, 216 (Moscow: Genesis, 2001)

15. N.A. Sirota, V.M. Yaltonsky, Prevention of drug addiction and alcoholism, 176 (Moscow: Academy, 2003)

16. E.G. Shubnikova, Theoretical approaches to the study of the structural components of the individual as the basis of the resilience of the prevention of addictive behavior, Russian Humanitarian Journal, 1, 14-20 (2013)

17. E.G. Shubnikova, Training of pedagogical university students for prevention of addictive behavior in childrens and youth's environment, 160 (Moscow: Modern Education, 2014)

18. N.S. Endler, J.D.A. Parker, Coping Inventory for Stressful Situations (CISS): Manual (Toronto: Multi-Health Systems, 1990)

19. T.L. Kryukova, E.V. Kuftyak, Questionnaire of ways of coping, Journal of Practical Psychology, 3, 93-103 (2007) 